Università degli Studi di Genova

DISEFIN - Series of Economic Working Papers

16126 Genova - via vivaldi 5 - Fax +39010 2095223

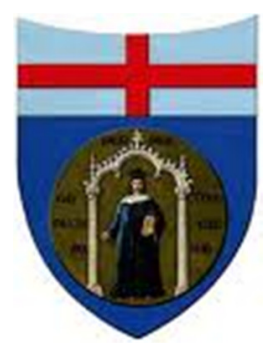

Paternalistic goods to improve income distribution: a political economy approach

Rosella Levaggi - Francesco Menoncin

wp n. 3/2012

April 2012 
"DISEFIN Working Papers on line"

series of economic working papers

published online by

Research Doctorate in

Economics and Finance of European Union

Ph.D School in New technologies and Social Sciences

University of Genoa

Founder:

Amedeo Fossati

Editor-in-Chief:

Marcello Montefiori

Editorial Board:

Paul De Grawe

Francesco Figari

Amedeo Fossati

Luca Gandullia

Eric Gaspérini

Andrea Monticini

Carlo Perroni

Web site:

http://www.disefin.unige.it 


\title{
Paternalistic goods to improve income distribution: a political economy approach
}

\author{
Rosella Levaggi \\ Department of Economics, \\ University of Brescia, \\ Italy
}

\author{
Francesco Menoncin \\ Department of Economics, \\ University of Brescia, \\ Italy
}

\begin{abstract}
In this article we show that when the provision of paternalistic goods is entwined with income distribution, the political decision process may prevent welfare maximisation. We model the decision process from a political economy perspective by assuming that the quantity of a paternalistic good to be produced, its regional distribution, and the equalisation grant are the result of a utilitarian bargaining process between a (relatively) rich Region and a poor one. Two cases are considered: a unitary and a federal State. The solution for a unitary State shows that First Best can be achieved only if the two Regions have the same bargaining power. In this case the level of income distribution is negatively correlated with the power of the rich Region. For a federal State we show that the result of the bargaining process always implies underprovision of the paternalistic good. Our model may explain the observed cross-national differences in the redistributive power of public policies.
\end{abstract}

Keywords: Paternalistic Goods, Income Distribution

Jel Classification: $118, H 77$ 


\section{Introduction}

The widespread diffusion of the welfare state has meant that the public sector has been financing the production of private goods either for paternalistic reasons ${ }^{1}$ or to improve income distribution both at individual level (through a subsidised price) and at regional level (through an equalisation grant). Health care and education represent some of the most interesting examples since they increase utility of the recipients, and produce positive spillovers on the utility of other individuals. In this article we show that when income redistribution is entwined with public provision of paternalistic goods, the political decision process may prevent the attainment of a welfare maximising solution.

We model the decision process from a political economy perspective by assuming that the quantity of a paternalistic good to be provided, its regional distribution and the equalisation grant are the result of a utilitarian bargaining process (Besley and Coate, 2003) between two Regions. Our approach shows that when income redistribution at inter-regional level relies on an equalisation grant based on the expenditure for paternalistic goods, the equilibrium quantity of the latter may not be efficient. Thus, the level of income redistribution may be lower than in First Best. Our findings are in line with Rodden (2010) who argues that the level of redistribution that public policies can achieve depends on the architecture of federalist institutions and, in particular, on the power that poor Regions have to ask for income redistribution. In fact, we build on this intuition to show that also the provision of paternalistic goods may be

\footnotetext{
${ }^{1}$ This is the concept of soft paternalism. See Schnellenbach (2012) for a review and an application to political economy.
} 
sub-optimal if the two objectives are pursued simultaneously.

Income distribution has been widely studied at theoretical and empirical level (see Padovano, 2012 for a review); the traditional literature mainly focuses on the assignment function (Bouton, Gassner, and Verardi, 2008; Gordon and Cullen, 2011; Bordignon, Manasse, and Tabellini, 2001) while the political economy literature (Inman and Rubinfield, 1997; Hillman, 2009; Besley and Coate, 2003; Feld, Fischer, and Kirchgaessner, 2010) has focused on the role that coalitions and bargaining have in the decision process. However, most of the models proposed by this literature consider the impact of public policies or the provision of public goods, possibly with spillovers. In our approach we model a good with a double nature: it is both a private good (supplied for free for paternalistic reasons) and a local public good with spillovers; we believe that this approach is more suitable to reflect the role of Government in areas such as health and education.

From a policy point of view, our model may explain the choices some federal States have made to finance paternalistic goods in the recent past. Wagstaff, van Doorslaer, van der Burg, Calonge, Christiansen, Citoni, Gerdtham, Gerfin, Gross, and Hakinnen (1999) and Wagstaff and van Doorslaer (2000) show that community rated financing systems are quite often used even when the price for taxfinanced health care is subsidised by an upper tier. The tax-financed part is usually related to an inter-regional equalisation grant while the community rated is usually financed locally; rich regions may prefer this mix in order to pursue equity at individual level without having to pay for the provision of other poor regions.

The final message of our paper is that when Central Government, or a super-national authority, aims at redistributing income, 
equalisation grants based on income rather than expenditure may be less distortive.

The paper is organised as follows: in Section 2 we present the model, Section 3 presents the main results in different regimes, Section 4 proposes some discussions and Section 5 concludes.

\section{The model}

A country, whose population is normalised to one, is divided into two Regions $i \in\{a, b\}$ with the same population (equal to $\frac{1}{2}$ ). The income owned by any agent in Region $i$ is $M^{k} \in\left[\underline{M}_{i}, \bar{M}_{i}\right]$ whose distribution is given by the function $\varphi_{i}\left(M^{k}\right)$ with

$$
\int_{\underline{M}_{i}}^{\bar{M}_{i}} \varphi_{i}\left(M^{k}\right) d M^{k}=\frac{1}{2} .
$$

Accordingly, total income in local authority $i$ is:

$$
Y_{i}=\int_{\underline{M}_{i}}^{\bar{M}_{i}} M^{k} \varphi_{i}\left(M^{k}\right) d M^{k},
$$

and we assume that $Y_{a}>Y_{b}$, i.e. Region $a$ is richer.

Utility is linear in income and in the consumption of a paternalistic good $Q$ whose individual taste parameter $\alpha$ is uniformly distributed in the range $[0, \beta]$ (thus, the weight of each agent preference is $\left.\beta^{-1}\right)$. The costs to produce $Q$ in Regions $a$ and $b$ are $v_{a}$ and $v_{b}$ respectively with $v_{b}>v_{a}$. However, the good is supplied for free, but access is restricted. We assume that $\beta>v_{b}$ which implies that the good would be demanded, even in a private market, at least by some individuals. 
The utility function for a representative individual $k$ living in local authority $i$ can be written as:

$V_{i}^{k}=\left(1-\tau_{i}\right) M^{k}+\mathbb{I}_{\alpha^{k}>p_{i}} \alpha^{k}+2\left(f_{i}\left(Q_{i}\right)+g_{i}\left(Q_{j}\right)\right), \quad i, j \in\{a, b\}$,

for $i \neq j$, where $\tau_{i}$ is the tax rate (equal for any agent in Region $i$ ) paid to finance the provision of $Q$, and $\mathbb{I}_{\alpha^{k}>p_{i}}$ is an indicator function whose value is 1 if $\alpha^{k}>p_{i}$ and 0 otherwise. The product $\mathbb{I}_{\alpha^{k}>p_{i}} \alpha^{k}$ represents the (private) utility derived from the consumption of $Q$. Its price is fully subsidised and its utility coincides with $\alpha^{k}$ but access is restricted to individuals with $\alpha^{k}>p_{i}$ where $p_{i}$ represents the marginal utility of the merit good the decision-maker is willing to finance.

As in Besley and Coate (2003), we have assumed that preferences for the impure public good have an additive form and are captured by functions $f_{i}\left(Q_{i}\right)$ and $g_{i}\left(Q_{j}\right)$ where $Q_{i}$ and $Q_{j}$ are the quantities of good $Q$ produced in the two jurisdictions. ${ }^{2}$

Functions $f_{i}(\cdot)$ and $g_{i}(\cdot)$ are assumed to be increasing and concave in their argument (decreasing marginal utility at community level), hence the utility of an additional unit depends on where it is produced. ${ }^{3}$ The level of publicness of the good depends on the functional form of both $f_{i}(\cdot)$ and $g_{i}(\cdot)$. In particular:

- for $f_{i}=g_{i}$, the good $Q$ is a public good;

- for $g_{i}=0$, the good $Q$ is a local public good;

\footnotetext{
${ }^{2}$ The function is multiplied by 2 for the sake of simplicity, as will be clear when aggregating the individual utility functions.

${ }^{3}$ For a distinction between global public goods and local public goods with spillovers see Levaggi (2010).
} 
- for $0<g_{i}<f_{i}$, the good $Q$ is a local public good with spillovers.

Total demand in local authority $i$ is given by:

$$
\begin{aligned}
Q_{i} & =\int_{\underline{M}_{i}}^{\bar{M}_{i}}\left(\int_{0}^{\beta} \frac{1}{\beta} \mathbb{I}_{\alpha^{k}>p_{i}} \varphi_{i}\left(M^{k}\right) d \alpha^{k}\right) d M^{k} \\
& =\int_{p_{i}}^{\beta} \frac{1}{\beta} d \alpha^{k} \int_{\underline{M}_{i}}^{\bar{M}_{i}} \varphi_{i}\left(M^{k}\right) d M^{k} \\
& =\frac{\beta-p_{i}}{2 \beta} .
\end{aligned}
$$

Welfare in local authority $i$ can be defined by aggregating equation (1):

$$
\begin{aligned}
W_{i} & \equiv \int_{\underline{M}_{i}}^{\bar{M}_{i}} \int_{0}^{\beta} V_{i}^{k} \frac{\varphi_{i}\left(M^{k}\right)}{\beta} d \alpha^{k} d M^{k} \\
& =\int_{\underline{M}_{i}}^{\bar{M}_{i}} \int_{0}^{\beta}\left(\left(1-\tau_{i}\right) M^{k}+\mathbb{I}_{\alpha^{k}>p_{i}} \alpha^{k}+2\left(f_{i}\left(Q_{i}\right)+g_{i}\left(Q_{j}\right)\right)\right) \frac{\varphi_{i}\left(M^{k}\right)}{\beta} d \alpha^{k} d M^{k} \\
& =\left(1-\tau_{i}\right) Y_{i}+\left(\int_{p_{i}}^{\beta} \alpha^{k} \frac{1}{\beta} d \alpha^{k}\right) \int_{\underline{M}_{i}}^{\bar{M}_{i}} \varphi_{i}\left(M^{k}\right) d M^{k}+f_{i}\left(Q_{i}\right)+g_{i}\left(Q_{j}\right) \\
& =\left(1-\tau_{i}\right) Y_{i}+\frac{1}{2}\left(\int_{p_{i}}^{\beta} \alpha^{k} \frac{1}{\beta} d \alpha^{k}\right)+f_{i}\left(Q_{i}\right)+g_{i}\left(Q_{j}\right)
\end{aligned}
$$

which can be written as:

$$
W_{i}=\left(1-\tau_{i}\right) Y_{i}+\frac{\beta^{2}-p_{i}^{2}}{4 \beta}+f_{i}\left(Q_{i}\right)+g_{i}\left(Q_{j}\right),
$$


where $\frac{\beta^{2}-p_{i}^{2}}{4 \beta}$ is the total (private) utility from consumption of $Q$. Its production is financed using a linear income tax at rate $\tau_{i}$ and an equalisation grant $G_{i}$ received from the Central Government. The local budget constraint can be accordingly written as

$$
Y_{i} \tau_{i}+G_{i}=v_{i} Q_{i},
$$

from which we obtain the local tax level

$$
\tau_{i}=\frac{v_{i} Q_{i}-G_{i}}{Y_{i}} .
$$

The grant $G_{i}$ used for guaranteeing horizontal equity coincides with a lump sum as suggested by Dahlby and Wilson (1994) and Smart (1998):

$$
G_{i}=\tau^{m}\left(\bar{Y}-Y_{i}\right)
$$

where $\tau^{m}$ and $\bar{Y}$ represent the national average tax rate and the standardised tax base respectively:

$$
\begin{aligned}
\tau^{m} & =\frac{\tau_{a} Y_{a}+\tau_{b} Y_{b}}{Y_{a}+Y_{b}}, \\
\bar{Y} & =\frac{Y_{a}+Y_{b}}{2} .
\end{aligned}
$$

Combining equations (3), (4) and (5) gives the following system:

$$
\begin{aligned}
& \tau_{a}=\frac{v_{a} Q_{a}-G_{a}}{Y_{a}}, \\
& \tau_{b}=\frac{v_{b} Q_{b}-G_{b}}{Y_{b}}, \\
& G_{a}=\frac{1}{2} \frac{Q_{a} v_{a}+Q_{b} v_{b}}{Y_{a}+Y_{b}}\left(Y_{b}-Y_{a}\right), \\
& G_{b}=\frac{1}{2} \frac{Q_{a} v_{a}+Q_{b} v_{b}}{Y_{a}+Y_{b}}\left(Y_{a}-Y_{b}\right) .
\end{aligned}
$$




\section{The decision process}

The provision of paternalistic goods may be granted either by Central Government (directly or through an agency) in the case of centralisation, or by an autonomous lower tier in the case of devolution. The relative advantages of these solutions have long been discussed in the literature (see, for example, Oates, 2005; Besley and Coate, 2003). Here, we assume there is no relative advantage in producing the good at a specific local level because we want to concentrate on the actual decision process that is going to determine the optimal provision of paternalistic goods at central level and the ensuing inter-regional income distribution. The literature does not propose a standard model and in our approach we have used the utilitarian bargaining solution proposed by Besley and Coate (2003) which allows us to capture the idea of the bargaining process described by Rodden (2010). The history behind each multi-level government organisation is different and in our paper we distinguish between the decision process in unitary and in federal governments.

\subsection{Unitary States}

In this setting each Region is represented at national level and it may have some decision power, but Central Government is able to impose any final decision. In particular, we rule out the possibility for any lower tier to veto decisions that may not be welfare maximising for its jurisdiction. The optimal provision of the paternalistic good can be defined by choosing the marginal agent $p_{i}$ and the problem can 
be written as:

$$
\begin{aligned}
\max _{p_{a}, p_{b}} W^{P E}= & \lambda\left(Y_{a}\left(1-\tau_{a}\right)+\frac{\beta^{2}-p_{a}^{2}}{4 \beta}+f_{a}\left(Q_{a}\right)+g_{a}\left(Q_{b}\right)\right) \\
& +(1-\lambda)\left(Y_{b}\left(1-\tau_{b}\right)+\frac{\beta^{2}-p_{b}^{2}}{4 \beta}+f_{b}\left(Q_{b}\right)+g_{b}\left(Q_{a}\right)\right)
\end{aligned}
$$

s.t.

$$
\begin{aligned}
& \tau_{i}=\frac{v_{i} Q_{i}-G_{i}}{Y_{i}}, \\
& G_{i}=\frac{1}{2} \tau^{m}\left(\bar{Y}-Y_{i}\right), \\
& 0 \leq Q_{i} \leq \frac{1}{2},
\end{aligned}
$$

where $\lambda$ and $1-\lambda$ are the relative strengths of Region $a$ and Region $b$ in the decision process, respectively. In a representative democracy where both Regions have the same population we might expect $\lambda=0.5$, but this might not be the case for several reasons. The local representatives may be constrained by lobbies or interest groups and the Regions where resources are drained to improve income redistribution have usually more power than the others. ${ }^{4}$ In appendix A we show that two levels $\lambda^{h}$ and $\lambda^{l}$ exist such that for $\lambda \in\left(\lambda^{l}, \lambda^{h}\right)$ an interior solution exists and it is the solution to the following system of FOCs:

$$
\begin{aligned}
& \frac{\partial f_{a}\left(Q_{a}\right)}{\partial Q_{a}}+\frac{\partial g_{b}\left(Q_{a}\right)}{\partial Q_{a}}-\frac{\partial g_{b}\left(Q_{a}\right)}{\partial Q_{a}}\left(\frac{\lambda-(1-\lambda)}{\lambda}\right)+p_{a}=v_{a}+\frac{Y_{a}-Y_{b}}{Y_{a}+Y_{b}}\left(\frac{\lambda-(1-\lambda)}{2 \lambda}\right) v_{a} \\
& \frac{\partial f_{b}\left(Q_{b}\right)}{\partial Q_{b}}+\frac{\partial g_{a}\left(Q_{b}\right)}{\partial Q_{b}}-\frac{\partial g_{a}\left(Q_{b}\right)}{\partial Q_{b}}\left(\frac{\lambda-(1-\lambda)}{\lambda}\right)+p_{b}=v_{b}+\frac{Y_{a}-Y_{b}}{Y_{a}+Y_{b}}\left(\frac{\lambda-(1-\lambda)}{2 \lambda}\right) v_{b} .
\end{aligned}
$$

\footnotetext{
${ }^{4}$ In Italy for example the Conferenza Stato Regioni is one of the most influential bodies as regards the decision on inter-regional income redistribution. Its composition is egalitarian (each Region has one representative), but in fact decisions are taken only if the richest and most influential Regions are in favour.
} 
Note that for $\lambda=0.5$ these FOCs become

$$
\begin{aligned}
& \frac{\partial f_{a}\left(Q_{a}\right)}{\partial Q_{a}}+\frac{\partial g_{b}\left(Q_{a}\right)}{\partial Q_{a}}+p_{a}=v_{a}, \\
& \frac{\partial f_{b}\left(Q_{b}\right)}{\partial Q_{b}}+\frac{\partial g_{a}\left(Q_{b}\right)}{\partial Q_{b}}+p_{b}=v_{b} .
\end{aligned}
$$

In this last case, the interpretation is similar to the equilibrium conditions for impure public goods: in each local authority it is optimal to produce the quantity for which the sum of the private marginal utility $(p)$ and the public marginal utility (taking externalities into due account) is equal to marginal cost. Equation (9) defines the optimal allocation corresponding to a First Best (FB) optimal solution.

This allows us to derive the following proposition:

Proposition 1. The solution to Problem (7) coincides with First Best only if the two Regions have the same weight (i.e. $\lambda=0.5$ ). If $\lambda>$ $0.5(\lambda<0.5)$ the paternalistic good is underprovided (overprovided) in both regions and income redistribution is lower (higher) than in First Best.

Proof. In appendix A we show that $\frac{\partial p_{i}}{\partial \lambda}>0$. For $\lambda>0.5$

$$
\frac{\partial f_{i}\left(Q_{i}\right)}{\partial Q_{i}}+\frac{\partial g_{j}\left(Q_{i}\right)}{\partial Q_{i}}+p_{i}-v_{i}>0
$$

i.e. the equilibrium quantity is lower than in First Best (i.e. it is underprovided). For $\lambda<0.5$

$$
\frac{\partial f_{i}\left(Q_{i}\right)}{\partial Q_{i}}+\frac{\partial g_{j}\left(Q_{i}\right)}{\partial Q_{i}}+p_{i}-v_{i}<0
$$

and the good is overprovided. 
For $\lambda<0.5$ a trade-off arises between efficiency and income distribution. To increase the latter, Central Government has to trade off efficiency, and the quantity of good to be produced will be higher than optimal. For $\lambda>0.5$ the provision is not efficient and income distribution is lower than in FB. It is interesting to note that the good is underprovided in both Regions: this implies that the richer Region is open to reducing the provision of the paternalistic good to its citizens if this is the price to pay for reducing the flow of resources toward the poorer Region. This is the essential problem faced by most federalist states which in fact determines the actual income distribution at regional level (Rodden, 2010).

The optimal values $p_{i}^{P E}, Q_{a}^{P E}$ and $Q_{b}^{P E}$ can be substituted in the welfare function which becomes:

$$
\begin{aligned}
W^{P E}= & \sum_{i=a, b}\left(Y_{i}-Q_{i}^{P E} v_{i}\right)+\frac{\beta}{2}-\frac{\sum_{i=a, b}\left(p_{i}^{P E}\right)^{2}}{4 \beta} \\
& +\sum_{i \neq j=a, b} f_{i}\left(Q_{i}^{P E}\right)+g_{i}\left(Q_{j}^{P E}\right) .
\end{aligned}
$$

For $\lambda=0.5$ total welfare is maximised; in all the other cases total welfare is sub-optimal but the welfare of each Region is higher (lower) than in First Best. In particular, if $\lambda>0.5$, the richer region is better-off than in First Best, even though the paternalistic good is underprovided. Two countervailing effects are at work: a welfare increase due to the reduction in the equalisation grant and a reduction due to the underprovision of the paternalistic good. However, the first effect is bigger than the second one and the rich region prefers underprovision to total welfare maximisation.

The solution with $\lambda=0.5$ can certainly be implemented when the two Regions have no decision power as regards the provision of 
the merit good; when the Government is organised in several tiers, the most likely outcome of the decision process is a bargaining between the different Regions. In a centralised democracy, if Regional Governments are powerful enough to have a voice (either in terms of bargaining power or in terms of participation in the decision process), the income redistribution and the quantity of paternalistic good to be produced depends on the relative power of each Region.

\subsection{Federal State}

In a federal State the lower tier has more power in the decision process and it may be allowed to veto policies that decrease its welfare. In the context of a federal State where the Regions may have some original power, the threat of secession may be more credible and the set of possible outcomes for a utilitarian bargaining solution may be restricted to the allocations that are (weakly) Pareto superior to devolution.

Devolution The good is produced by the two lower tiers in an autonomous way. Each local government sets its own level of taxation and service production according to its preferences and resources. The upper tier of government sets the equalisation grant; this actor is the last one to move, i.e. it sets the grant after each lower level has set expenditure and taxation. In this setting each local Government does not fully take into account the positive spillovers the production of $Q$ generates (Koethenbuerger, 2008) and it may suffer from fiscal illusion since it may assume that $G_{i}$ is a fixed quantity that does not depend on the level of total expenditure. The problem for 
each authority can be written as:

$$
\begin{aligned}
& \max _{p_{i}} Y_{i}\left(1-\tau_{i}\right)+\frac{\beta^{2}-p_{i}^{2}}{4 \beta}+f_{i}\left(Q_{i}\right)+g_{i}\left(Q_{j}\right) \\
& \text { s.t. } \\
& \tau_{i}=\frac{v_{i} Q_{i}-G_{i}}{Y_{i}}
\end{aligned}
$$

The FOC can be written as:

$$
\begin{aligned}
& \frac{\partial f_{a}\left(Q_{a}\right)}{\partial Q_{a}}+p_{a}=v_{a}, \\
& \frac{\partial f_{b}\left(Q_{b}\right)}{\partial Q_{b}}+p_{b}=v_{b} .
\end{aligned}
$$

The quantity produced and demanded will clearly be lower than in the First Best equilibrium. Total welfare in this case can be written as:

$W^{D}=\sum_{i=a, b}\left(Y_{i}-Q_{i}^{D} v_{i}\right)+\frac{\beta}{2}-\frac{\sum_{i=a, b}\left(p_{i}^{D}\right)^{2}}{4 \beta}+\sum_{i \neq j=a, b} f_{i}\left(Q_{i}^{D}\right)+g_{i}\left(Q_{j}^{D}\right)$.

Total welfare is lower than in first best: the reduction in welfare due to a sub-optimal provision of paternalistic goods offsets the increase in welfare due to reduction in the tax rate, as shown by traditional literature (Tresch, 2002; Oates, 1972). However, the reduction in expenditure in the merit good reduces the equalisation grant and the richer local authority may be better-off in this suboptimal solution. To explain how this happens, let's examine Figure 1 where the different effects are presented.

The first best optimal allocation is represented by the combination $\left(Q_{a}^{*}, Q_{b}^{*}\right)$. Given a specific level of expenditure, Central Government sets the lump sum grant $G_{i}$ so that the net income of each local authority is $\left(Y_{a}^{*}, Y_{b}^{*}\right)$ and total welfare is $W_{a}^{*}+W_{b}^{*}$. In 


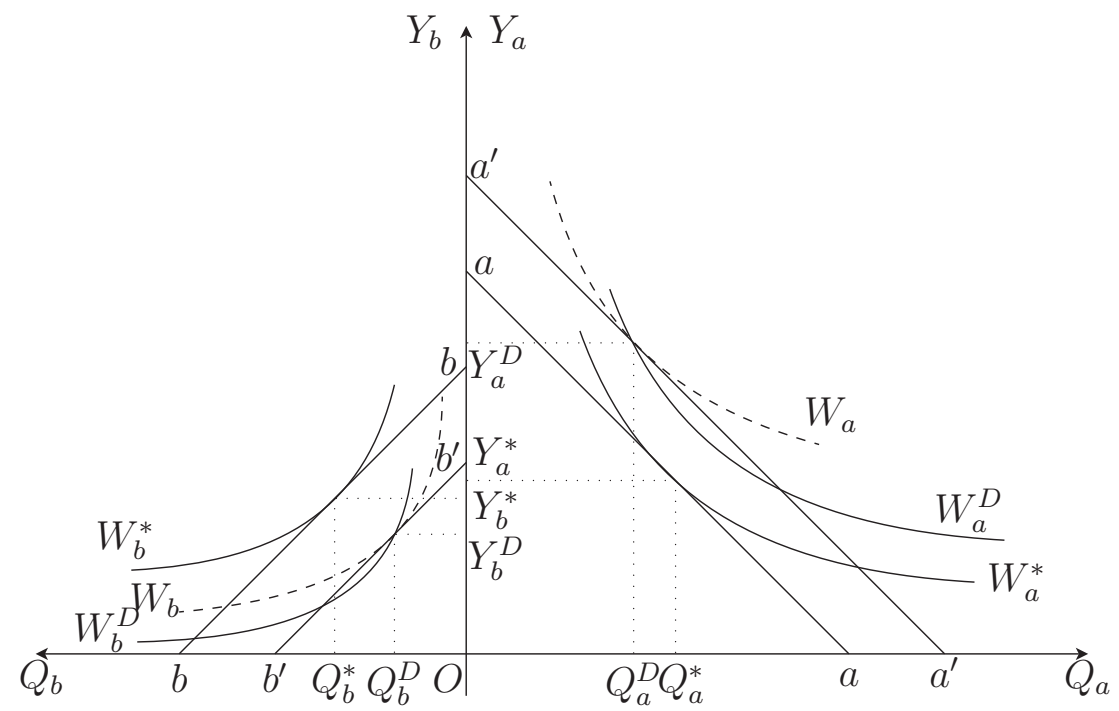

Figure 1: Centralisation vs fiscal federalism: welfare analysis 
the devolution, each local authority does not perceive the positive externalities its production creates and the optimal quantity of paternalistic good is reduced to $\left(Q_{a}^{D}, Q_{b}^{D}\right)$. Expenditure and the average tax rate decreases, there is less need for the equalisation grant. This is the reason why the budget constraint shifts from $a a$ to $a^{\prime} a^{\prime}$ and from $b b$ to $b^{\prime} b^{\prime}$ respectively. $B$ certainly suffers a welfare loss, but $A$ is better-off: the quantity of paternalistic goods produced is lower than the optimal amount, but the income effect brought about by the reduction in the equalisation grant may compensate such reduction. We can then conclude that while

$$
\begin{aligned}
W_{a}^{F B}+W_{b}^{F B} & >W_{a}^{D}+W_{b}^{D}, \\
W_{b}^{F B} & >W_{b}^{D},
\end{aligned}
$$

for $A$ we have

$$
W_{a}^{F B}<W_{a}^{D} .
$$

This gain is directly related to the income difference: the greater the difference between the two local authorities, the better-off the wealthier local authority in decentralisation.

\subsection{Optimal solution for a federal State}

For a federal State we should restrict the bargaining to the subset of centralised solutions that can be considered a (weak) Pareto improvements on devolution. The problem can be written as: 


$$
\begin{aligned}
\max _{p_{a}, p_{b}} W^{F}= & \lambda\left(Y_{a}\left(1-\tau_{a}\right)+\frac{1}{4} \frac{\beta^{2}-p_{a}^{2}}{\beta}+f_{a}\left(Q_{a}\right)+g_{a}\left(Q_{b}\right)\right) \\
& +(1-\lambda)\left(Y_{b}\left(1-\tau_{b}\right)+\frac{1}{4} \frac{\beta^{2}-p_{b}^{2}}{\beta}+f_{b}\left(Q_{b}\right)+g_{b}\left(Q_{a}\right)\right)
\end{aligned}
$$

s.t.

$\tau_{i}=\frac{v_{i} Q_{i}-G_{i}}{Y_{i}}$

$G_{i}=\frac{1}{2} \tau^{m}\left(\bar{Y}-Y_{i}\right)$,

$W_{a}^{F} \geq W_{a}^{D}$,

$W_{b}^{F} \geq W_{b}^{D}$

where $W_{a}^{D}$ and $W_{b}^{D}$ are the welfare levels that each Region can achieve in a decentralised system.

The objective function is the same as for the unitary state, but here we have two more constraints: the welfare of each Region must be at least equal to the decentralised solution. In principle a solution that improves welfare from decentralisation may exist, but it will not be First Best: this is because the richer Region has a higher utility in decentralisation than in FB as shown in the previous section. This allows us to obtain the following proposition:

Proposition 2. A centralised solution may be compatible with a federal State, but in this case the scope for income redistribution is reduced. A federal State cannot achieve a first best optimal allocation and the quantity supplied is too low.

Proof. In Appendix B we compute the curvatures of the indifference curve for $a$ and $b$. This allows us to draw Figure 2. The solid lines represent the indifference curves for welfare in decentralisation which cross at $\left(Q_{a}^{D}, Q_{b}^{D}\right)$. The region compatible with the maximization of Equation (14) is represented by the shaded area. 


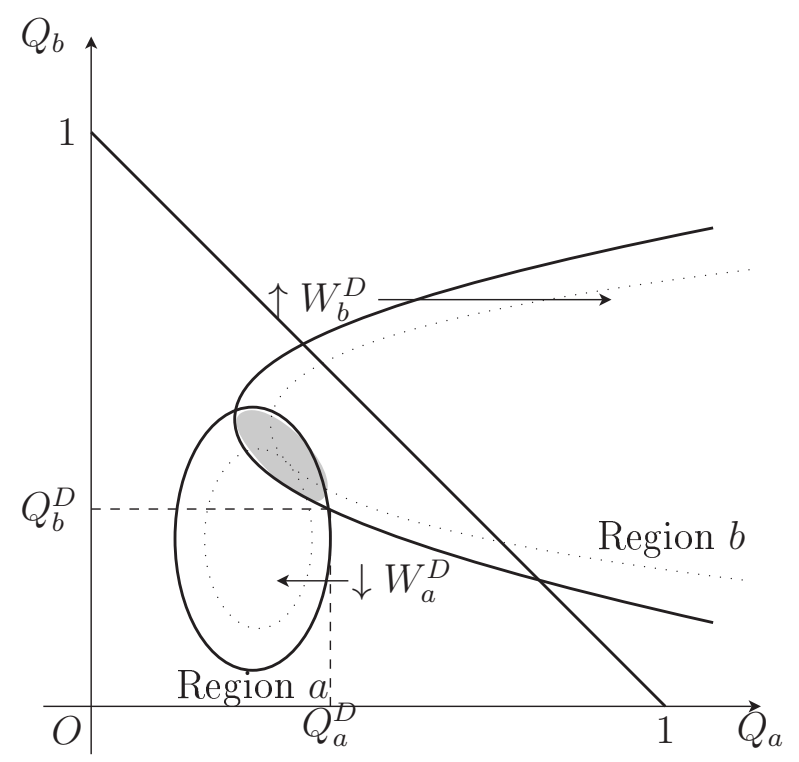

Figure 2: Indifference curves for Regions $a$ and $b$ in decentralised setting 
Without spillovers (i.e. $g_{i}=0$ ) the indifference curves are tangent at $\left(Q_{a}^{D}, Q_{b}^{D}\right)$, with slope given by $-\frac{v_{a}}{v_{b}}$. With spillovers, the two lines still cross at $\left(Q_{a}^{D}, Q_{b}^{D}\right)$, but because of their curvature an area exists where a bargaining solution may improve the decentralise solution. However, $\left(Q_{a}^{*}, Q_{b}^{*}\right)$ will not be in this area because, as shown above, $W_{a}^{F B}<W_{a}^{D}$.

In this case the scope for income redistribution is reduced. First Best cannot be achieved with spillovers and the quantity supplied is always lower than in First Best, but there is a range of values for which $W^{F}$ can be considered a Pareto improvement on devolution. The latter depends on spillovers: the higher the spillover, the greater the scope for cooperation.

\section{Discussion}

The model presented in this paper starts from a simple consideration: when the income redistribution and the production of paternalistic goods are strictly related, pursuing efficiency and equity is feasible only if the lower tiers have the same bargaining power. This is because a decentralised decision is preferred by rich Regions to the First Best solution. This is due to the sum of two countervailing effects: a decrease in welfare brought about by the lack of coordination, which means that the total quantity of paternalistic goods is not optimal, and a reduction in the equalisation grant. If there is a gainer, it will always be represented by the rich region, while the poor region will certainly be worse-off.

It is in this framework that any centralised decision has to be made. If we rule out the existence of a benevolent planner that has the power to impose unweighed total welfare maximisation, the 
more likely solution at Central level is a bargaining between the lower tiers. In our paper we show that the solution will be the First Best only under two conditions: there are no spillovers and/or both local authorities have the same bargaining power. Both conditions are unlikely to be verified: most paternalistic goods have a public good characteristic that spreads its beneficial effects outside the region where they are produced. In a representative democracy each Region should have the same power (or a power directly correlated to the number of its inhabitants), but this might not necessarily be the case. Elected representatives may be captured and rich local authorities may threaten secession if their conditions are not accepted. The Regional power may depend on the history of each country. In particular, we show that income redistribution may be lower in $\mathrm{Fe}-$ deral States than in unitary ones, and this finding is supported by the empirical evidence. ${ }^{5}$

From a policy point of view, we argue that two above-mentioned countervailing effects may explain some of the anomalies observed in federal systems. In Switzerland, for example, wealthy Cantons are trying to keep public health care expenditure at its lowest level and do not even use matching grants made available by the Confederation. This behaviour is certainly anomalous: the same cantons increase the local tax rate to supplement community rated insurances whose price is not subsidised. However, this behaviour is quite rational if the equalisation grant depends on the level of expenditure: in this case the Canton may pay to reduce public health care expenditure.

To avoid these strategic behaviours a possible solution may be

\footnotetext{
${ }^{5}$ For a discussion of this problem see Evans (2002) and Feld, Fischer, and Kirchgaessner (2010).
} 
to separate the production of paternalistic goods from inter-regional income equalisation. In this way, the production of the paternalistic good would be efficient and could be used to redistribute income within each community while inter-regional income redistribution could be more efficiently pursued through an equalisation grant based on income.

\section{Conclusions}

Income redistribution has received renewed interest, both at theoretical and empirical level in the recent past where the Government has become more and more involved with the production of paternalistic goods with spillovers. These goods are used to redistribute income at individual level (through a subsidy on their price) and at regional level (through an equalisation grant based on the level of total expenditure). Income distribution has been widely discussed by the traditional and the empirical literature and there is no consensus on the most efficient level to pursue this goal.

In this paper we abstract from the assignment problem and we study the political decision process that determines the level of income redistribution. We assume that income redistribution is set at national level through a utilitarian bargaining model where each Region has a different weight. We show that the level of income redistribution is related to the relative weight that rich regions have in relation to the poor regions, as one might expect.

However, given that the quantity of the paternalistic good is simultaneously determined with income redistribution, also this supply, which affects individual income redistribution, depends on this weight. In a centralised system only a benevolent planner that 
weights the utility of all the Regions in the same way will be able to reach an FB optimal allocation. In all the other cases income redistribution will be lower or higher according to the weight of the rich region. As a consequence, the paternalistic good will be underprovided or overprovided. This implies that the use of these grants may generate itself important inefficiencies as regards the provision of paternalistic goods. If the rich region has more power it will try to reduce total expenditure, even though this means underprovision of the paternalistic good itself, with the risk of choosing to underprovide an essential service. The rationale for this choice is to improve income distribution: if rich regions have considerable power and equalisation of resource was based on income rather than expenditure, the level of income distribution would be even lower. However, the cost that society pays may be rather high in terms of income distribution at individual level.

\section{References}

Besley, T., and S. Coate (2003): "Centralized versus decentralized provision of local public goods: a political economy approach," Journal of Public Economics, 87, 2611-2637.

Bordignon, M., P. Manasse, and G. Tabellini (2001): "Optimal Regional Redistribution under Asymmetric Information," American Economic Review, 91(3), 709-723.

Bouton, L., M. Gassner, and V. Verardi (2008): "Redistributing income under fiscal vertical imbalance," European Journal of Political Economy, 24(2), 317 - 328. 
Dahlby, B., and L. S. Wilson (1994): "Fiscal Capacity, Tax Effort, and Optimal Equalization Grants," Canadian Journal of Economics, 27(3), 657-672.

Evans, R. G. (2002): "Financing health care:taxation and the alternatives," in Funding health care: options for Europe, ed. by E. Mossialos, A. Dixon, J. Figueras, and J. Kutzin, European Observatory on Health Care systems, chap. 2, pp. 31-58. Open University Press.

Feld, L., J. Fischer, and G. Kirchgaessner (2010): "The Effect Of Direct Democracy On Income Redistribution: Evidence For Switzerland," Economic Inquiry, 48(4), 817-840.

Gordon, R. H., and J. B. Cullen (2011): "Income redistribution in a Federal system of governments," Journal of Public Economics, $(0),-$.

Hillman, A. L. (2009): Public Finance and Public Policy. Cambridge University Press, 2nd edition edn.

Inman, R. P., and D. L. Rubinfield (1997): "The Political Economy of Federalism," in Perspectives on Public Choice: A Handbook, ed. by D. C. Mueller, pp. 73-105. Cambridge University Press.

Koethenbuerger, M. (2008): "Revisiting the "Decentralization Theorem"-On the role of externalities," Journal of Urban Economics, 64(1), 116-122.

Levaggi, R. (2010): "From Local to Global Public Goods: How Should We Write the Utility Function," Economic Modelling, 27(5), 1040-1042. 
Oates, W. E. (1972): Fiscal Federalism. Harcourt, Brace Jovanovich, New York.

Oates, W. E. (2005): "Toward A Second-Generation Theory of Fiscal Federalism," International Tax and Public Finance, 12, 349373, 10.1007/s10797-005-1619-9.

Padovano, F. (2012): "The drivers of interregional policy choices: Evidence from Italy," European Journal of Political Economy, 28(3), 324-340.

Rodden, J. (2010): "Federalism and Inter-Regional Distribution," in The Political Economy of Inter-Regional Fiscal Flows, ed. by M. E. Nuria Bosch, and A. S. Olle. Edward Elgar.

Schnellenbach, J. (2012): "Nudges and norms: On the political economy of soft paternalism," European Journal of Political Economy, 28(2), $266-277$.

Smart, M. (1998): "Taxation and deadweight loss in a system of Intergovernmental Transfer," The Canadian Journal of Economics, 31(1), 189-206.

Tresch, R. (2002): Public Finance: A normative view. Academic Press, San Diego, 2nd edn.

Wagstaff, A., and E. van Doorslaer (2000): "Chapter 34 Equity in health care finance and delivery," in Handbook of Health Economics, ed. by A. J. Culyer, and J. P. Newhouse, vol. 1 of Handbook of Health Economics, chap. 34, pp. 1803-1862. Elsevier. 
Wagstaff, A., E. van Doorslaer, H. van der Burg, S. Calonge, T. Christiansen, G. Citoni, U.-G. Gerdtham, M. Gerfin, L. Gross, and U. Hakinnen (1999): "Equity in the finance of health care: some further international comparisons," Journal of Health Economics, 18(3), 263-290. 


\section{A Solution to the centralised problem}

We can substitute the first three constraints in equation (7) in the maximisation problem. The condition $0 \leq Q_{i} \leq \frac{1}{2}$ should be written as a set of four constraints in terms of $p_{i}$ as $p_{i} \geq 0$, and $p_{i} \leq \beta$, for $i=a, b$. The tax rate can be written in terms of $p_{i}$ using equation 6. The problem can be written as:

$$
\begin{aligned}
\max _{p_{a}, p_{b}} W^{P E}= & \lambda\left(Y_{a}\left(1-\frac{\frac{\left(\beta-p_{a}\right)\left(3 Y_{a}+Y_{b}\right)}{2 \beta} v_{a}+\frac{\left(\beta-p_{b}\right)\left(Y_{a}-Y_{b}\right)}{2 \beta} v_{b}}{2 Y_{a}\left(Y_{a}+Y_{b}\right)}\right)\right. \\
& \left.+\frac{\beta^{2}-p_{a}^{2}}{4 \beta}+f_{a}\left(\frac{\beta-p_{a}}{2 \beta}\right)+g_{a}\left(\frac{\beta-p_{b}}{2 \beta}\right)\right) \\
& +(1-\lambda)\left(Y_{b}\left(1-\frac{\frac{\left(\beta-p_{a}\right)\left(Y_{b}-Y_{a}\right)}{2 \beta} v_{a}+\frac{\left(Y_{a}+3 Y_{b}\right)\left(\beta-p_{b}\right)}{2 \beta} v_{b}}{2 Y_{b}\left(Y_{b}+Y_{a}\right)}\right)\right. \\
& \left.+\frac{\beta^{2}-p_{b}^{2}}{4 \beta}+f_{b}\left(\frac{\beta-p_{b}}{2 \beta}\right)+g_{b}\left(\frac{\beta-p_{a}}{2 \beta}\right)\right) \\
& -l_{1}\left(-p_{a}\right)-l_{2}\left(-p_{b}\right)-l_{3}\left(p_{a}-\beta\right)-l_{4}\left(p_{b}-\beta\right),
\end{aligned}
$$

where $l_{i}, i \in\{1,2,3,4\}$ are the Lagrangian multipliers. This problem can be solved using Khun Tucker conditions. In order to skip many implausible cases, we have decided to follow a different strategy. An internal solution exists (with $0<p_{i}<\beta$ and $l_{i}=0$ ) if the following FOCs and SOCs are verified:

$$
\begin{gathered}
\frac{\partial W^{P E}}{\partial p_{a}}=-\frac{2 \lambda\left(\frac{\partial f_{a}\left(Q_{a}\right)}{\partial Q_{a}}+p_{a}-v_{a}\right)\left(Y_{a}+Y_{b}\right)+2(1-\lambda) \frac{\partial g_{b}\left(Q_{a}\right)}{\partial Q_{a}}\left(Y_{a}+Y_{b}\right)+v_{a}\left(Y_{a}-Y_{b}\right)(1-2 \lambda)}{4 \beta\left(Y_{a}+Y_{b}\right)}=0, \\
\frac{\partial W^{P E}}{\partial p_{b}}=-\frac{2(1-\lambda)\left(\frac{\partial f_{b}\left(Q_{b}\right)}{\partial Q_{b}}+p_{b}\right)\left(Y_{a}+Y_{b}\right)+2 \lambda \frac{\partial g_{a}\left(Q_{b}\right)}{\partial Q_{b}}\left(Y_{a}+Y_{b}\right)+v_{b}\left(Y_{a}-Y_{b}\right)(1-2 \lambda)}{4 \beta\left(Y_{a}+Y_{b}\right)}=0,
\end{gathered}
$$


$\begin{aligned} \frac{\partial^{2} W^{P E}}{\partial p_{a}^{2}} & =\frac{-2 \lambda\left(-\frac{1}{2 \beta} \frac{\partial^{2} f_{a}\left(Q_{a}\right)}{\partial Q_{a}^{2}}+1\right)\left(Y_{a}+Y_{b}\right)+\frac{1}{\beta}(1-\lambda) \frac{\partial^{2} g_{b}\left(Q_{a}\right)}{\partial Q_{a}^{2}}\left(Y_{a}+Y_{b}\right)}{4 \beta\left(Y_{a}+Y_{b}\right)}<0, \\ \frac{\partial^{2} W^{P E}}{\partial p_{b}^{2}} & =\frac{-2(1-\lambda)\left(-\frac{1}{2 \beta} \frac{\partial^{2} f_{b}\left(Q_{b}\right)}{\partial Q_{b}^{2}}+1\right)\left(Y_{a}+Y_{b}\right)+\frac{1}{\beta} \lambda \frac{\partial^{2} g_{a}\left(Q_{b}\right)}{\partial Q_{b}^{2}}\left(Y_{a}+Y_{b}\right)}{4 \beta\left(Y_{a}+Y_{b}\right)}<0 .\end{aligned}$

We can find the relationship between $p_{a}, p_{b}$, and $\lambda$ by using the implicit function theorem on equation (15):

$$
\begin{aligned}
\frac{\partial p_{a}}{\partial \lambda} & =-\frac{\frac{\partial W^{P E}}{\partial \lambda}}{\frac{\partial W^{P E}}{\partial p_{a}}} \\
& =-\frac{-2 \frac{1}{\lambda} \frac{\partial g_{b}\left(Q_{a}\right)}{\partial Q_{a}}\left(Y_{a}+Y_{b}\right)-v_{a}\left(Y_{a}-Y_{b}\right) \frac{1}{\lambda}}{2 \lambda\left(-\frac{1}{2 \beta} \frac{\partial^{2} f_{a}\left(Q_{a}\right)}{\partial Q_{a}^{2}}+1\right)\left(Y_{a}+Y_{b}\right)-\frac{1}{\beta}(1-\lambda) \frac{\partial^{2} g_{b}\left(Q_{a}\right)}{\partial Q_{a}^{2}}\left(Y_{a}+Y_{b}\right)}>0 \\
\frac{\partial p_{b}}{\partial \lambda} & =-\frac{\frac{\partial W^{P E}}{\partial \lambda}}{\frac{\partial W^{P E}}{\partial p_{b}}} \\
& =-\frac{-2 \frac{1}{\lambda}\left(\frac{\partial f_{b}\left(Q_{b}\right)}{\partial Q_{b}}+p_{b}\right)\left(Y_{a}+Y_{b}\right)-v_{b}\left(Y_{a}-Y_{b}\right) \frac{1}{\lambda}}{2(1-\lambda)\left(-\frac{1}{2 \beta} \frac{\partial^{2} f_{b}\left(Q_{b}\right)}{\partial Q_{b}^{2}}+1\right)\left(Y_{a}+Y_{b}\right)-\frac{1}{\beta} \lambda \frac{\partial^{2} g_{a}\left(Q_{b}\right)}{\partial Q_{b}^{2}}\left(Y_{a}+Y_{b}\right)}>0 .
\end{aligned}
$$

Since $p_{a}$ and $p_{b}$ are both increasing in $\lambda$, all the orthogonal corner solutions cannot be verified $\left(p_{i}=0, p_{j}=\beta\right)$. Given that $\lambda$ can only take values in the interval $[0,1]$, the maximum value for $p_{i}$ will be found for $\lambda=1$ and the minimum for $\lambda=0$. Let's examine these two cases. 


\section{A.1 Case with $\lambda=0$}

The first derivatives of the objective function become

$$
\begin{aligned}
\frac{\partial W^{P E}}{\partial p_{a}} & =-\frac{2 \frac{\partial g_{b}\left(Q_{a}\right)}{\partial Q_{a}}\left(Y_{a}+Y_{b}\right)+v_{a}\left(Y_{a}-Y_{b}\right)}{4 \beta\left(Y_{a}+Y_{b}\right)}<0, \\
\frac{\partial W^{P E}}{\partial p_{b}} & =-\frac{2\left(\frac{\partial f_{b}\left(Q_{b}\right)}{\partial Q_{b}}+p_{b}\right)\left(Y_{a}+Y_{b}\right)+v_{b}\left(Y_{a}-Y_{b}\right)}{4 \beta\left(Y_{a}+Y_{b}\right)}<0 .
\end{aligned}
$$

Since both are negative, a corner solution exists: $p_{i}=0$ and $Q_{i}=\frac{1}{2}$. This implies that a value $\lambda^{l}$ exists which discriminates between a corner solution and an interior solution.

\section{A.2 Case with $\lambda=1$}

The first derivatives of the objective function become

$$
\begin{aligned}
\frac{\partial W^{P E}}{\partial p_{a}} & =-\frac{2\left(\frac{\partial f_{a}\left(Q_{a}\right)}{\partial Q_{a}}+p_{a}-v_{a}\right)\left(Y_{a}+Y_{b}\right)-v_{a}\left(Y_{a}-Y_{b}\right)}{4 \beta\left(Y_{a}+Y_{b}\right)}, \\
\frac{\partial W^{P E}}{\partial p_{b}} & =-\frac{2 \frac{\partial g_{a}\left(Q_{b}\right)}{\partial Q_{b}}\left(Y_{a}+Y_{b}\right)-v_{b}\left(Y_{a}-Y_{b}\right)}{4 \beta\left(Y_{a}+Y_{b}\right)} .
\end{aligned}
$$

The constraints may be binding, but also in this case a value $\lambda^{h}$ exists which discriminates between an interior and a corner solution. 


\section{B Existence of a solution to the federal State problem}

To show that a solution to the problem presented in equation (14) exists, it is sufficient to show the existence of a non-empty set of Pareto improving solutions.

A sufficient condition for the existence of this set is that a crossing point exists for the two following indifference curves:

$W_{i}^{D}=Y_{i}\left(1-\tau_{i}^{D}\right)+\frac{1}{4} \frac{\beta^{2}-\left(p_{i}^{D}\right)^{2}}{\beta}+f_{i}\left(Q_{i}^{D}\right)+g_{i}\left(Q_{j}^{D}\right), i, j \in\{a, b\}$,

and at that point one is convex and the other is concave.

The decentralised solution presented in equation (12) is an equilibrium solution, i.e. at that point the two curves cross. Let's now examine their curvature, i.e. the second derivative of the indifference curve.

\section{B.1 Region $a$}

Welfare in terms of $Q_{a}$ and $Q_{b}$ can be written as:

$$
\begin{aligned}
W_{a}^{D}= & Y_{a}\left(1-\frac{Q_{a} v_{a}\left(3 Y_{a}+Y_{b}\right)+Q_{b} v_{b}\left(Y_{a}-Y_{b}\right)}{2 Y_{a}\left(Y_{a}+Y_{b}\right)}\right)+\beta\left(Q_{a}-Q_{a}^{2}\right) \\
& +f_{a}\left(Q_{a}\right)+g_{a}\left(Q_{b}\right) .
\end{aligned}
$$

The marginal rate of substitution between $Q_{a}$ and $Q_{b}$ can be found using the implicit function theorem. The first derivatives of 
$W_{a}$ with respect to $Q_{a}$ and $Q_{b}$ are

$$
\begin{aligned}
\frac{\partial W_{a}^{D}}{\partial Q_{a}} & =-\frac{v_{a}\left(3 Y_{a}+Y_{b}\right)}{2\left(Y_{a}+Y_{b}\right)}+\beta\left(1-2 Q_{a}\right)+f_{a}^{\prime}\left(Q_{a}\right), \\
\frac{\partial W_{a}^{D}}{\partial Q_{b}} & =-\frac{v_{b}\left(Y_{a}-Y_{b}\right)}{2\left(Y_{a}+Y_{b}\right)}+g_{a}^{\prime}\left(Q_{b}\right),
\end{aligned}
$$

and, accordingly, we have

$$
\frac{\partial Q_{a}}{\partial Q_{b}}=-\frac{\frac{\partial W_{a}^{D}}{\partial Q_{b}}}{\frac{\partial W_{a}^{D}}{\partial Q_{a}}}=-\frac{-\frac{v_{b}\left(Y_{a}-Y_{b}\right)}{2\left(Y_{a}+Y_{b}\right)}+g_{a}^{\prime}\left(Q_{b}\right)}{-\frac{v_{a}\left(3 Y_{a}+Y_{b}\right)}{2\left(Y_{a}+Y_{b}\right)}+\beta\left(1-2 Q_{a}\right)+f_{a}^{\prime}\left(Q_{a}\right)} .
$$

Since the FOC implies

$$
f_{a}^{\prime}\left(Q_{a}\right)+\beta\left(1-2 Q_{a}\right)=v_{a},
$$

the previous derivative can be written as

$$
\frac{\partial Q_{a}}{\partial Q_{b}}=-\frac{v_{b}}{v_{a}}+2 \frac{\left(Y_{a}+Y_{b}\right)}{v_{a}\left(Y_{a}-Y_{b}\right)} g_{a}^{\prime}\left(Q_{b}\right),
$$

which is negative if

$$
g_{a}^{\prime}\left(Q_{b}\right)<\frac{v_{b}}{2} \frac{Y_{a}-Y_{b}}{Y_{a}+Y_{b}} .
$$

It is interesting to note that without spillovers, i.e. $g_{a}^{\prime}\left(Q_{b}\right)=0$, the indifference curve would be a straight line with slope $\frac{\partial Q_{a}}{\partial Q_{b}}=-\frac{v_{b}}{v_{a}}$.

The curvature depends on the sign of the second derivative:

$$
\begin{aligned}
\frac{\partial^{2} Q_{a}}{\partial Q_{b}^{2}} & =\frac{\partial}{\partial Q_{b}}\left(-\frac{\frac{\partial W_{a}^{D}}{\partial Q_{b}}}{\frac{\partial W_{a}^{D}}{\partial Q_{a}}}\right)=\frac{g_{a}^{\prime \prime}\left(Q_{b}\right)\left(Y_{a}-Y_{b}\right) \frac{v_{a}}{2\left(Y_{a}+Y_{b}\right)}}{\left(-\frac{v_{a}\left(3 Y_{a}+Y_{b}\right)}{2\left(Y_{a}+Y_{b}\right)}+\beta\left(1-2 Q_{a}\right)+f_{a}^{\prime}\left(Q_{a}\right)\right)^{2}} \\
& =\frac{g_{a}^{\prime \prime}\left(Q_{b}\right)\left(Y_{a}-Y_{b}\right) \frac{v_{a}}{2\left(Y_{a}+Y_{b}\right)}}{\left(-\frac{v_{a}\left(3 Y_{a}+Y_{b}\right)}{2\left(Y_{a}+Y_{b}\right)}\right)^{2}}<0 .
\end{aligned}
$$


We can conclude that this indifference curve is concave.

\section{B.2 Region $b$}

The same method can be used to find the curvature of the indifference curve for $W_{b}^{D}$. Welfare in terms of $Q_{a}$ and $Q_{b}$ can be written as:

$$
\begin{aligned}
W_{b}= & Y_{b}\left(1-\frac{Q_{a} v_{a}\left(Y_{b}-Y_{a}\right)+Q_{b} v_{b}\left(Y_{a}+3 Y_{b}\right)}{2 Y_{b}\left(Y_{b}+Y_{a}\right)}\right)+\beta\left(Q_{b}-Q_{b}^{2}\right) \\
& +f_{b}\left(Q_{b}\right)+g_{b}\left(Q_{a}\right)
\end{aligned}
$$

whose derivatives with respect to $Q_{a}$ and $Q_{b}$ are

$$
\begin{aligned}
& \frac{\partial W_{b}^{D}}{\partial Q_{a}}=-\frac{v_{a}\left(Y_{b}-Y_{a}\right)}{2\left(Y_{b}+Y_{a}\right)}+g_{b}^{\prime}\left(Q_{a}\right), \\
& \frac{\partial W_{b}^{D}}{\partial Q_{b}}=-\frac{v_{b}\left(Y_{a}+3 Y_{b}\right)}{2\left(Y_{b}+Y_{a}\right)}+\beta\left(1-2 Q_{b}\right)+f_{b}^{\prime}\left(Q_{b}\right),
\end{aligned}
$$

and, hence

$$
\frac{\partial Q_{a}}{\partial Q_{b}}=-\frac{\frac{\partial W_{b}^{D}}{\partial Q_{b}}}{\frac{\partial W_{b}^{D}}{\partial Q_{a}}}=-\frac{-\frac{v_{b}\left(Y_{a}+3 Y_{b}\right)}{2\left(Y_{b}+Y_{a}\right)}+\beta\left(1-2 Q_{b}\right)+f_{b}^{\prime}\left(Q_{b}\right)}{-\frac{v_{a}\left(Y_{b}-Y_{a}\right)}{2\left(Y_{b}+Y_{a}\right)}+g_{b}^{\prime}\left(Q_{a}\right)} .
$$

Since the FOC implies

$$
f_{b}^{\prime}\left(Q_{b}\right)+\beta\left(1-2 Q_{b}\right)=v_{b},
$$

we have

$$
\frac{\partial Q_{a}}{\partial Q_{b}}=\frac{v_{b}\left(Y_{a}-Y_{b}\right)}{v_{a}\left(Y_{b}-Y_{a}\right)-2\left(Y_{b}+Y_{a}\right) g_{b}^{\prime}\left(Q_{a}\right)}<0
$$


Again, without spillovers, the indifference curve would be a straight line $\left(\frac{\partial Q_{a}}{\partial Q_{b}}=-\frac{v_{b}}{v_{a}}<0\right)$.

The curvature is

$$
\begin{aligned}
\frac{\partial^{2} Q_{a}}{\partial Q_{b}^{2}} & =\frac{\partial}{\partial Q_{b}}\left(-\frac{\frac{\partial W_{b}}{\partial Q_{b}}}{\frac{\partial W_{b}}{\partial Q_{a}}}\right) \\
& =-\frac{\left(-2 \beta+f_{b}^{\prime \prime}\left(Q_{b}\right)\right) \frac{1}{2\left(Y_{b}+Y_{a}\right)}\left(-v_{a}\left(Y_{b}-Y_{a}\right)+2\left(Y_{b}+Y_{a}\right) g_{b}^{\prime}\left(Q_{a}\right)\right)}{\left(-\frac{v_{a}\left(Y_{b}-Y_{a}\right)}{2\left(Y_{b}+Y_{a}\right)}+g_{b}^{\prime}\left(Q_{a}\right)\right)^{2}}>0
\end{aligned}
$$

and so we can conclude that this indifference curve is convex.

In $\left(Q_{a}^{D}, Q_{b}^{D}\right)$ the two curves must cross, and they are tangent only for $f_{i}=g_{i}=0$. This implies that their graphical representation should look like figure 2 in the main text. 


\section{Working Papers recently published}

(The complete list of working papers can be found at http.//www.disefin.unige.it)

n.2/2012 Gabriele Cardullo, "Public Sector Wage Bargaining, Unemployment, and Inequality ", February 2012

n.1/2012 Amedeo Fossati, "The Italian Tradition in Public Finance: an Annotated Bibliografy of Mauro Fasiani", January 2012

n.7/2011 Amedeo Fossati, Marcello Montefiori, "Adverse Selection in Elderly Care", November 2011

n.6/2011 Paolo Cremonesi, Enrico di Bella, Marcello Montefiori, Luca Persico, "A self-reported work sampling to assess the Emergency Department's costs", October 2011

n.5/2011 Enrico di Bella, Luca Persico, Matteo Corsi, "A Multivari-ate Analysis Of The Space Syntax Output For The Definition Of Strata In Street Security Surveys", September 2011

n.4/2011 Elena Briata, "Marginal tax rates, tax revenues and inequal-ity. Reagan's fiscal policy", July 2011

n.3/2011 Francesco Copello, Cristiana Pellicanò, "Esemplificazione della Data Envelopment Analysis per la valutazione di effi-cienza in una grande azienda ospedaliera universitaria"

n.2/2011 Stefano Capri, Rosella Levaggi, "Shifting the risk in pricing and reimbursement schemes? A model of risk-sharing agree-ments for innovative drugs"

n.1/2011 Cinzia Di Novi, "The Indirect Effect of Fine Particulate Matter on Health through Individuals' Life-style"

n.4/2010 Angelo Baglioni, Andrea Monticini, "Why does the Interest Rate Decline Over the Day? Evidence from the Liquidity Cri-sis"

n.3/2010 Amedeo Fossati: "The double taxation of savings: the Ital-ian debate revisited"

n.2/2010 Andrea Monticini, David Peel, Giacomo Vaciago: "The im-pact of ECB and FED announcements on the Euro Interest Rates"

n.1/2010 Amedeo Fossati: "Vilfredo Pareto and the methodology of the Italian tradition in public finance" 